\title{
A 39-year-old Man With Left Shoulder Pain: Comparing 3- and 5-Point Triage Scales
}

\author{
Renea L. Beckstrand \\ Brigham Young University - Provo, renea@byu.edu \\ Ellen K. Sanders
}

Follow this and additional works at: https://scholarsarchive.byu.edu/facpub

Part of the Other Nursing Commons

\section{Original Publication Citation}

Beckstrand, R. L., \& Sanders, E. K. (2003). Triage decisions. A 39-year-old man with left shoulder pain: comparing 3-and 5-point triage scales. Journal of Emergency Nursing, 29(4), 387-389.

\section{BYU ScholarsArchive Citation}

Beckstrand, Renea L. and Sanders, Ellen K., "A 39-year-old Man With Left Shoulder Pain: Comparing 3- and 5-Point Triage Scales" (2003). Faculty Publications. 5296.

https://scholarsarchive.byu.edu/facpub/5296 


\section{A 39-year-old Man \\ With Left Shoulder Pain: Comparing 3- and 5-Point \\ Triage Scales}

Authors: Renea L. Beckstrand, PhD, RN, CCRN, and Ellen K. Sanders, RN, Orem, Utah, and Idaho Falls, Idaho

Section Editor: Diane Gurney, RN, MS, CEN

Renea L. Beckstrand, Timpanogas Chapter, is Associate Professor, College of Nursing, Brigham Young University, Provo, Utah. Ellen K. Sanders, Teton Intermountain Chapter, is Staff Nurse, Emergency Department, Eastern Idaho Regional Medical Center, Idaho Falls, Idaho.

For reprints, write: Renea L. Beckstrand, PhD, RN, CCRN, 825 S 890 East, Orem, UT 84097-4710; E-mail:renea_beckstrande@byu.edu. J Emerg Nurs 2003;29:387-9.

Copyright (C) 2003 by the Emergency Nurses Association. $0099-1767 / 2003 \$ 30.00+0$

doi: $10.1067 / \mathrm{men} .2003 .122$
A 39-year-old Hispanic man arrives in the emergency department complaining of pain in the area of his left shoulder.

The triage nurse thinks, "Pain to the left shoulder could be referred cardiac pain or possibly Kehr's sign, which is referred pain associated with splenic rupture."

She quickly assesses his ABCs. He is alert, his color is normal, skin warm and dry, he is not splinting his abdomen and denies having abdominal pain. She palpates his pulse as she asks when the shoulder pain started. The patient tells her he has had the pain for weeks. He explains that he broke his clavicle 2 months ago in a car crash and had an operation that was supposed to fix it. Now the triage nurse thinks, ".... bone infection, or could he possibly have fractured it again? Could it still be splenic rupture delayed?"

The nurse asks him to describe the location of the pain and the patient carefully takes off his shirt. On physical examination, the patient has approximately $5.0 \mathrm{~cm}$ of what appears to be a relatively large-diameter stainless steel orthopedic pin, protruding from his left clavicle toward and external to his shoulder at approximately a 20-degree angle. The skin around the pin entrance site looks somewhat scarred, but there is no erythema or sign of local skin infection. Upon further questioning, the patient explains that he had come to the emergency department to see if he could get the nail removed because it was causing him pain each time it became hooked on clothing and because it was painful to lie on either his left side or abdomen.

Vital signs are: tympanic temperature, $37.6^{\circ} \mathrm{C}$; pulse, 89 beats per minute and regular; respirations, 18 per minute; blood pressure, 123/89 mm Hg; and oxygen saturation, $93 \%$ on room air. The patient weighs $93 \mathrm{~kg}$ and he rates his pain level at 2/10. 


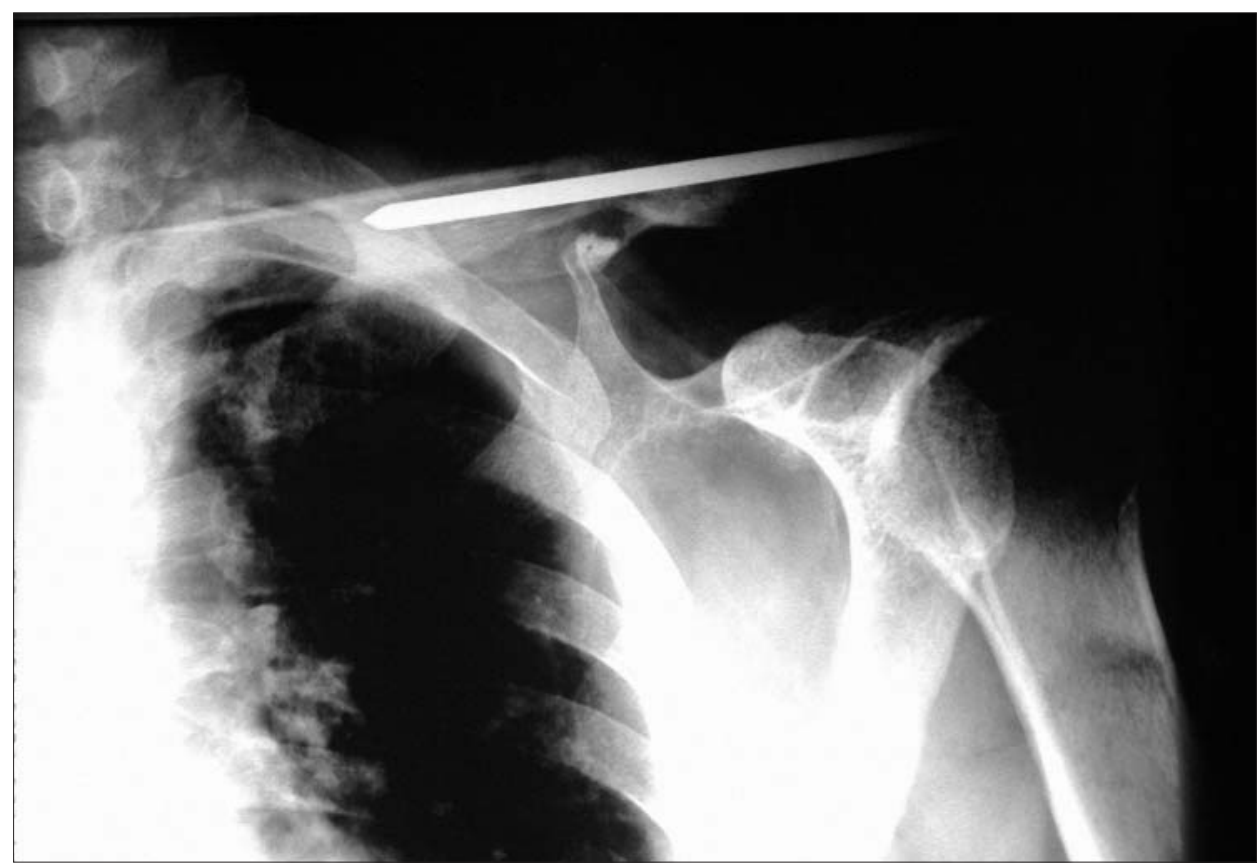

FIGURE 1

Radiograph of patient's left shoulder. Orthopedic pin is visible through healed midshaft clavicular fracture. Approximately $5 \mathrm{~cm}$ of the pin protruded outside of the body.

The patient was sent for radiographs of the left shoulder. Four different radiographic views of the clavicle and shoulder were taken. The AP film showed a healed mid point clavicular fracture spanned by a long orthopedic pin (Figure 1). There was also some mild osteoporosis noted in the shoulder.

\section{Discussion}

Once the radiographs were completed, the orthopedic physician was called in for removal of the pin. The clavicular entry site was locally anesthetized, scrubbed, and draped using sterile procedures. The physician pushed on the area around the site with his gloved left hand while manually applying traction on the pin with his right hand using sterile clamps to grip the pin. With a twisting and pulling motion the pin was removed from the clavicle. Upon further examination, the pin measured a total of $18 \mathrm{~cm}$ in length. A sterile dressing was placed on the site. No antibiotics or pain medications were ordered. Follow up was scheduled for 6 weeks.

This patient presented with a partially extravasated pin, after his injury had healed, but his original fracture- clavicular, bears mention. Between 4 and 15 percent of all fractures seen in the emergency department involve the clavicle. ${ }^{1}$ Clavicular fractures are the most common childhood fracture with most occurring in the first 7 years of life. ${ }^{1,2}$ This patient's fracture was positioned in the middle third of the bone, which is where $60 \%$ of all clavicle fractures occur. ${ }^{2}$

\section{Using another 5-level triage scale, the Emergency Severity Index, this patient would be categorized as a level III, "multiple resources needed." \\ Radiographs and an orthopedic consult constitute multiple resources.}

A typical presentation of a clavicle fracture would include the patient complaining of tenderness and swelling in the clavicle area and some noticeable deformity at the injured site. The patient frequently will present to the emergency department with the affected arm turned inward and downward being supported by the patient's other, 
uninjured, arm. ${ }^{2}$ Caring for patients with fractured clavicles ranges from simple to more complex treatment. Immobilization of a displaced clavicle fracture with a figure-of-eight brace is often successful. ${ }^{2}$ If the fracture is not displaced, simple immobilization with a sling may suffice. If the fracture is severely displaced, an open reduction may be necessary. Adults generally heal over a 4 - to 6-week period. ${ }^{2}$

\section{Section Editor's Note}

\section{ASSIGNING A TRIAGE LEVEL}

This patient offers a good example of someone who might be rated one way on a 3-level triage, and another on a 5point. Using the standard 3-level triage, this patient would be the lowest level, or non-urgent. Using the Canadian ED Triage \& Acuity Scale and the Australian Triage Scale, both 5-level triage scales, this patient would be categorized as the lowest level, also called non-urgent, and target time to physician (assessment and treatment) estimated to be 2 hours. However, using another 5-level triage scale, the Emergency Severity Index, this patient would be categorized as a level III, "multiple resources needed." Radiographs and an orthopedic consult constitute multiple resources. Which scale is used in your emergency department? Does it work for you?

\section{REFERENCES}

1. Querioz R, Sucov A. The Clavicle and Scapula in Emergency Radiology. Schwartz D, Reisderff E, editors. New York: McGrawHill; 2000. p. 17-34.

2. Uchara DT, Rudzinski JP. Injuries to the shoulder complex and humerus, In Emergency Medicine: A Comprehensive Study Guide. Tintinally JE, Kelen GD, Stapcynski JS, editors. New York: McGraw-Hill; 2000. p. 1783-91.

Submissions to this column are welcomed and encouraged. Submissions may be sent to:

Diane Gurney, RN, MS, CEN

261 Bishops Terrace, Hyannis, MA 02601

501862-5970•dgurney@capecodhealth.org 